\title{
Presentation of stable angina pectoris among women and South Asian people
}

\author{
M. Justin Zaman MBBS MSc, Cornelia Junghans PhD, Neha Sekhri MBBS, Ruoling Chen MD PhD, \\ Gene S. Feder MD, Adam D. Timmis MBBChir MD, Harry Hemingway MBBChir
}

$\infty \quad$ See related commentary by Diercks and Miller, page 631

\section{ABSTRACT}

Background: There is speculation that women and South Asian people are more likely than men and white people to report atypical angina and that they are less likely to undergo invasive management of angina. We sought to determine whether atypical symptoms of angina pectoris in women and South Asians impacted clinically important outcomes and clinical management.

Methods: We prospectively identified 2189 South Asian people and 5605 white people with recent-onset chest pain at 6 chest-pain clinics in the United Kingdom. We documented hospital admissions for acute coronary syndromes, coronary deaths as well as coronary angiography and revascularization procedures.

Results: Atypical chest pain was reported by more women than men $(56.5 \%$ vs $54.5 \%, p<0.054)$ and by more South Asian patients than white patients $(59.9 \%$ vs $52.5 \%$, $p<0.001$ ). Typical symptoms were associated with coronary death or acute coronary syndromes among women (hazard ratio [HR] 2.30, 95\% Cl 1.70-3.11, $p<0.001$ ) but not among men (HR 1.23, 95\% Cl 0.96-1.57, $p=0.10$ ). Typical symptoms were associated with coronary outcomes in both South Asian and white patients. Among those with typical symptoms, women (HR $0.76,95 \% \mathrm{Cl} 0.63-0.92$, $p=0.004)$ and South Asian patients (HR 0.52, 95\% Cl $0.41-0.67, p<0.001)$ were less likely than men and white patients to receive angiography.

Interpretation: Compared to those with atypical chest pain, women and South Asian patients with typical pain had worse clinical outcomes. However, sex and ethnic background did not explain differences in the use of invasive procedures.

Une version française de ce résumé est disponible à l'adresse www.cmaj.ca/cgi/content/full/179/7/659/DC1

CMAJ 2008;179(7):659-67

$\mathrm{T}$ he description of symptoms, articulated by patients and recorded by doctors, remains a cornerstone of diagnosis. History-taking is central to the diagnosis of chronic stable angina pectoris, yet "textbook" descriptions have been largely derived and validated among white men. A meta-analysis that included almost 25000 people from 31 countries $^{2}$ found that the prevalence of typical symptoms of stable angina pectoris is as high or higher in women compared with men. In addition, the prevalence of typical symptoms is higher among people of South Asian descent than among white people. ${ }^{3}$ Despite these findings, it is widely perceived that women, ${ }^{4-6}$ South Asian people ${ }^{7-9}$ and other ethnic minorities with suspected ischemia are more likely than white men to report atypical features of pain..$^{10,11}$ This has been attributed to vasospastic and microvascular angina in women ${ }^{12}$ and to the higher prevalence of diabetes mellitus ${ }^{13}$ and socio-economic deprivation ${ }^{7}$ among South Asian people.

Both women $^{14,15}$ and South Asian ${ }^{16,17}$ patients are less likely than men and white people in general to undergo invasive management of angina. It has been proposed that differences in how these patients describe their symptoms may contribute to inequalities in medical care, ${ }^{8,18}$ because the diagnostic validity of symptoms plays an important role in deciding appropriate clinical management. ${ }^{19}$ However, it is not known if the distinction between typical and atypical symptoms of chronic stable angina pectoris has similar prognostic value for subsequent coronary events in women and men of white and South Asian ethnic backgrounds.

We sought to determine whether the description of angina pain as typical or atypical is associated with coronary outcomes. We also investigated whether differences in how patients report their symptoms is related to the clinical management of angina.

\section{Methods}

\section{Population}

We recruited 11082 consecutive patients with recent onset chest pain from 6 rapid-access chest-pain clinics in the United Kingdom from Jan. 2, 1996, to Dec. 31, 2002. These ambulatory care clinics are run by cardiology teams and accept same-day referrals from family physicians of patients with recent-onset chest pain suspected to be stable angina pectoris. These clinics do not accept referrals of patients who have previously been suspected to have coronary disease, who have received a diagnosis of coronary disease, or who received a diagnosis of acute coronary syndromes on the day of the visit.

From the Department of Epidemiology and Public Health (Zaman, Junghans, Chen, Hemingway), University College London; Newham University Hospital (Sekhri); and Barts and the London (Feder, Timmis), Queen Mary's School of Medicine and Dentistry, London, UK 
Data about baseline patient characteristics and pain descriptions were electronically recorded by the cardiologists using identical databases, details of which have been reported previously. ${ }^{20}$ We included only patients with suspected incident angina in our analyses, similar to an earlier study. ${ }^{21}$ If a patient's first language was not English, or if a patient did not attend the clinic with an English-speaking family member or friend, a trained health advocate assisted the patient during the visit. The selection of patients is shown in Figure 1.

Ethical approval was obtained from a multiregional ethics committee (Multi-centre Research Ethics Committee /02/04/095). The National Patient Information Advisory Group gave us permission to link anonymized data sets without obtaining individual patient consent.

\section{Baseline characteristics}

Cardiologists recorded ethnic background as Asian, white, black or other. In a validation study that included 34 consecutive patients, we found that the cardiologist's assessment of ethnic background was consistent with how $88 \%$ of patients

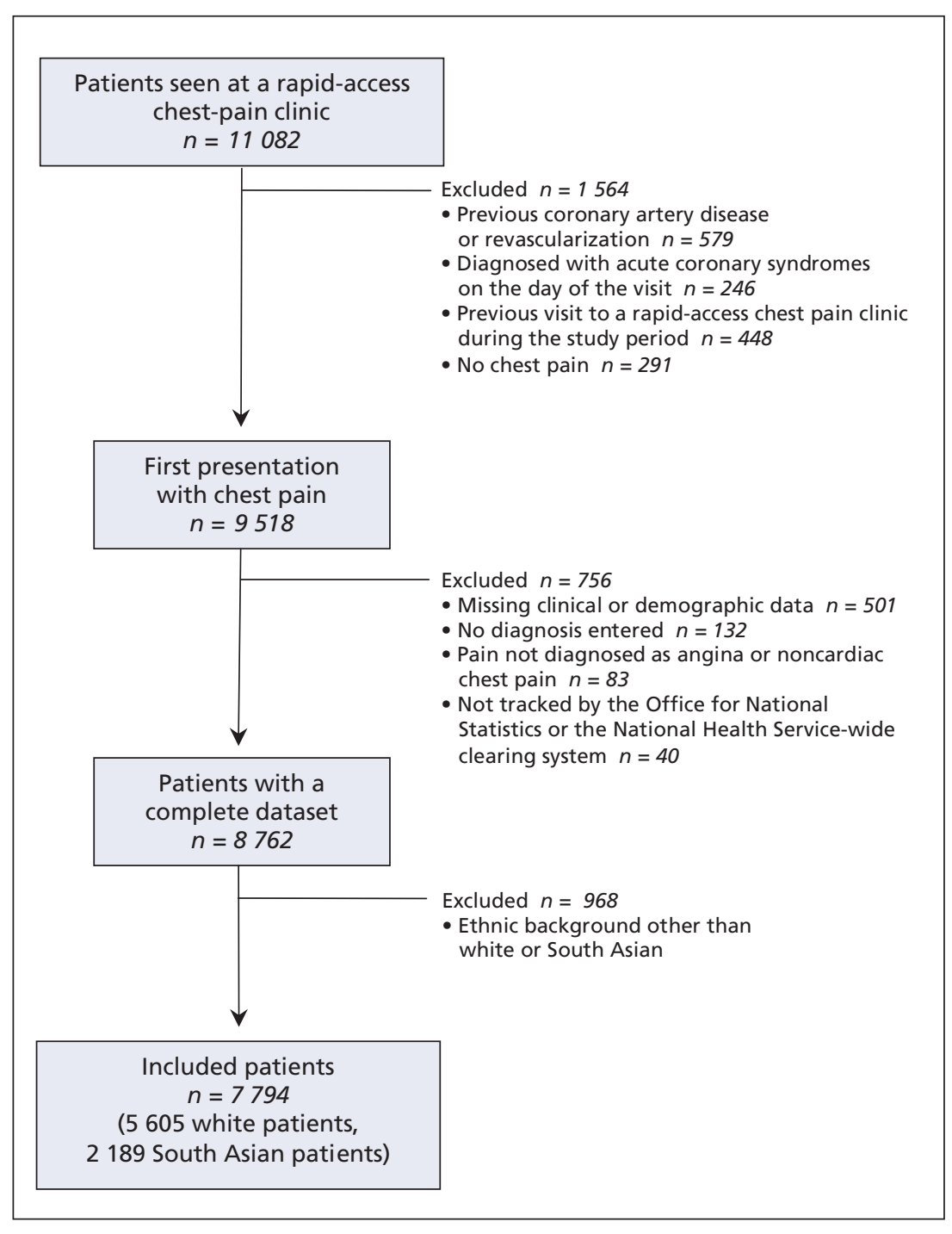

Figure 1: Selection of patients for inclusion in the study. self-identified on the 2001 census (kappa statistic 0.77). For the purpose of our study, we defined South Asian as people who self-identified as Bangladeshi, Indian, Pakistani or Sri Lankan. Cardiologists recorded data about smoking status, history of hypertension or diabetes and medication use. Exercise electrocardiography was performed if it was deemed appropriate by the cardiologist.

\section{Descriptors of chest pain}

While obtaining the patient's history, cardiologists recorded a descriptor for each of the following 4 components of chest pain: character (aching, constricting, stabbing, nondescript), site (central, left-sided, right-sided, submammary, epigastric, other), duration (seconds, $<5$ minutes, 5-15 minutes, 15-30 minutes, hours or variable) and precipitating factors (none, exercise, exercise and rest, stress, eating, other). Based on the Diamond-Forrester classification, ${ }^{1}$ we considered typical pain to be that which the patient described as having a constricting quality, being located centrally or on the left-side of the chest, lasting between a few seconds and 15 minutes, and being provoked by exercise. We used a "symptom score" to classify the patient's description of pain as typical (3 or more characteristics of typical pain) or atypical ( 2 or fewer characteristics). The cardiologist made an overall assessment of the patient's symptoms as typical or atypical ("cardiologist summary"). At the end of the consultation, the cardiologist diagnosed the cause of the patient's chest pain as either angina or noncardiac chest pain.

\section{Outcomes and follow-up}

Using unique National Health Service numbers, we were able to monitor mortality among patients by use of data from the Office for National Statistics. We were able to monitor hospital admissions, coronary angiography and revascularisation by use of the national Hospital Episode Statistics, supplied by the National Health Service Wide Clearing System. Successful matching was achieved for $99.5 \%$ of the cohort. Causes of death and admission to hospital were coded according to the International Classification of Diseases, 10th revision (ICD-10). Our primary outcome, used in all reports from this data set, ${ }^{17,22}$ was death from coronary artery disease (ICD-10 codes I20-I25) as well as hospital admission because of an acute coronary syndrome (acute myocardial infarction, ICD-10 codes I21-I23) and unstable angina (ICD-10 codes I20.0-120.9, 124.0, I24.8, I24.9). The management outcomes were receipt of coronary angiography as a confirmatory diagnostic test and subsequent coronary revascularization (either percutaneous coronary intervention or coronary artery bypass surgery, whichever was first) within 3 years of a clinic visit. 


\section{Statistical analysis}

To examine baseline clinical and chest-pain characteristics, we recorded age as a continuous variable (median, interquartile range) and compared these characteristics using the Student's $t$ test. Proportions were compared using the $\chi^{2}$ statistic. To examine the probability of receiving a diagnosis of angina according to exercise electrocardiography results, cardiologist summary or symptom score, we used likelihood ratios with 95\% confidence intervals (CI). When calculating likelihood ratios, we excluded patients who had a positive exercise electrocardiography result (182 South Asian patients, 668 white patients) to remove the potential influence of a positive result on formulating a diagnosis of angina.

To examine the prognostic validity of cardiologist summaries and symptom scores for coronary outcomes, we performed adjusted Cox proportional hazards regression by sex and ethnic background. A hazard ratio less than 1 represents a better prognosis. We compared hazard ratios between sex and ethnic background using a test of interaction. ${ }^{23}$ We performed adjusted Cox proportional hazards regression by sex and ethnic background to assess the relation between typicallity of chest pain and coronary outcomes, and receipt of coronary angiography and revascularization. In these analyses, a hazard ratio less than 1 represents a lower likelihood of receiving the procedure. We adjusted for age (as a continuous variable), sex or ethnic background, diabetes, smoking, hypertension, revascularization (percutaneous or bypass surgery), result of exercise electrocardiography (positive or negative), and use of antianginal medications ( $\beta$-blocker, calcium antagonist, oral nitrate, nicorandil) or secondary prevention medication (acetylsalicylic acid, statin, angiotensin-converting enzyme $[\mathrm{ACE}]$ inhibitor),

\section{Results}

In total, we included 7794 people: 2676 white women, 2929 white men, 980 South Asian women and 1209 South

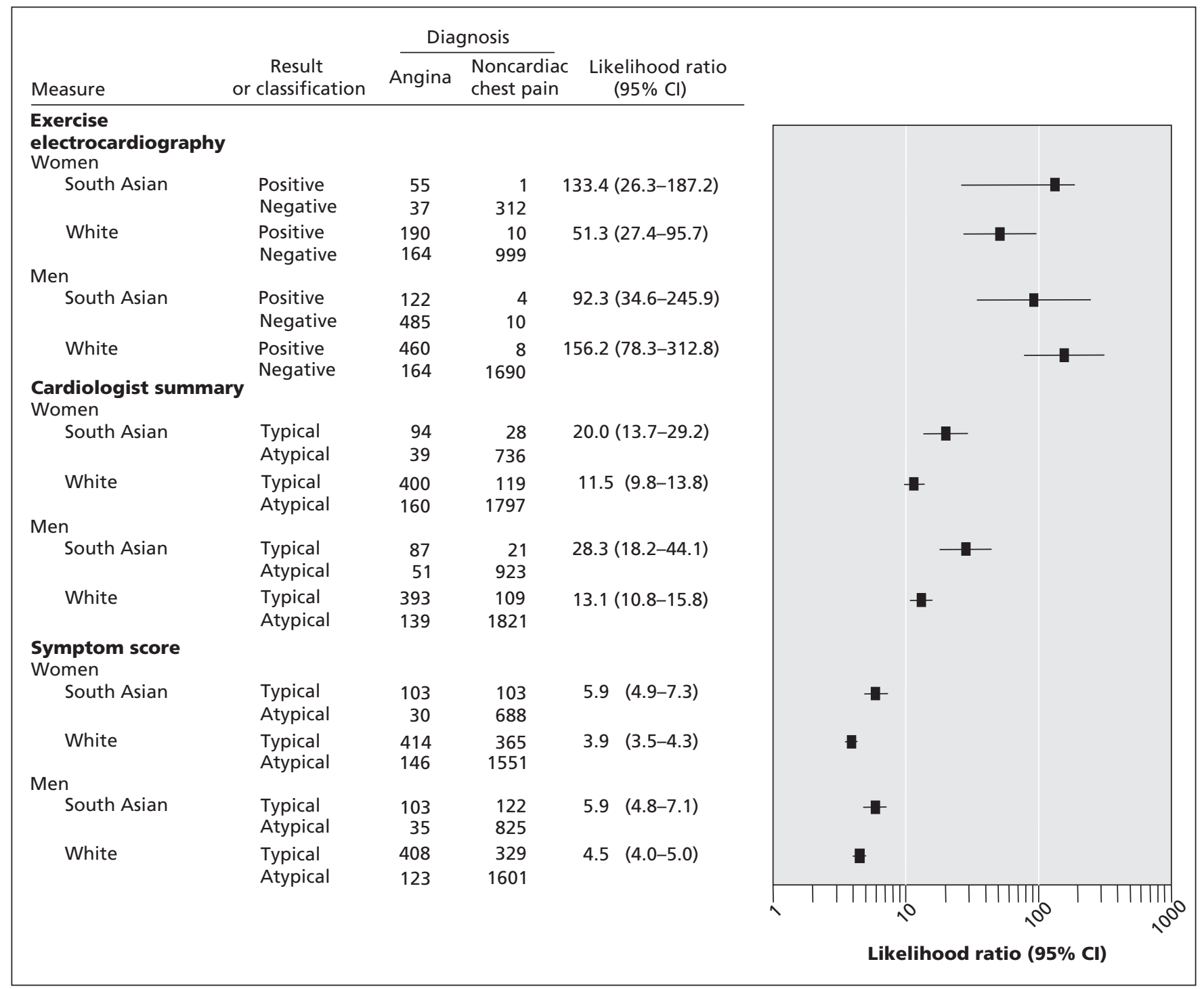

Figure 2: Likelihood of diagnosis of angina according to exercise electrocardiography result, cardiologist summary or symptom score, by sex and ethnic background. Note: $\mathrm{Cl}=$ confidence interval. 
Table 1: Baseline clinical and chest-pain characteristics of patients included in the study (part 1 of 2)

\begin{tabular}{|c|c|c|c|c|c|c|}
\hline \multirow{3}{*}{$\begin{array}{l}\text { Characteristic } \\
\text { Age, yr, median }\end{array}$} & \multicolumn{3}{|c|}{ Women; no. (\%) of patients* } & \multicolumn{3}{|c|}{ Men; no. $(\%)$ of patients* } \\
\hline & \multirow{2}{*}{$\begin{array}{c}\begin{array}{c}\text { South Asian } \\
n=980\end{array} \\
50.6(42-58)\end{array}$} & \multirow{2}{*}{$\begin{array}{c}\text { White } \\
n=2676\end{array}$} & \multirow{2}{*}{$\begin{array}{l}p \text { value } \\
<0.001\end{array}$} & $\begin{array}{l}\text { South Asian } \\
n=1209\end{array}$ & $\begin{array}{c}\text { White } \\
n=2929\end{array}$ & \multirow{2}{*}{$\begin{array}{l}p \text { value } \\
<0.001\end{array}$} \\
\hline & & & & $49.8(41-59)$ & 54.7 (45-65) & \\
\hline \multicolumn{7}{|l|}{ Risk factor } \\
\hline Smoker & 35 (3.6) & $683(25.5)$ & $<0.001$ & $320(26.3)$ & 924 (31.6) & 0.001 \\
\hline Diabetes & $209(21.3)$ & $165 \quad(6.1)$ & $<0.001$ & $219(18.1)$ & $207 \quad(7.1)$ & 0.001 \\
\hline Hypertension & $367(37.5)$ & $1017(38.0)$ & 0.759 & $365(30.2)$ & 875 (29.9) & 0.84 \\
\hline \multicolumn{7}{|l|}{ Medication } \\
\hline \multicolumn{7}{|l|}{ Secondary prevention } \\
\hline ASA & $232(23.7)$ & $843(31.5)$ & $<0.001$ & $328(27.1)$ & $1028(35.1)$ & $<0.001$ \\
\hline Statin & $61 \quad(6.2)$ & $371(13.9)$ & $<0.001$ & $117 \quad(9.7)$ & $445 \quad(15.2)$ & $<0.001$ \\
\hline ACE inhibitor & $62(6.3)$ & $171 \quad(6.4)$ & 0.94 & $83 \quad(6.9)$ & $213 \quad(7.3)$ & 0.64 \\
\hline \multicolumn{7}{|l|}{ Antianginals } \\
\hline$\beta$-blocker & $155(15.8)$ & $557(20.8)$ & 0.001 & $214(17.7)$ & $701 \quad(23.9)$ & $<0.001$ \\
\hline Calcium antagonist & $99(10.1)$ & $474(17.7)$ & $<0.001$ & $102 \quad(8.4)$ & $537 \quad(18.3)$ & $<0.001$ \\
\hline Oral nitrate & $67 \quad(6.8)$ & $229 \quad(8.6)$ & 0.09 & $94 \quad(7.8)$ & $300(10.2)$ & 0.014 \\
\hline Nicorandil & $3(0.3)$ & $38 \quad(1.4)$ & 0.005 & $9 \quad(0.7)$ & $60 \quad(2.1)$ & 0.003 \\
\hline \multicolumn{7}{|c|}{$\begin{array}{l}\text { Patient description of } \\
\text { pain }\end{array}$} \\
\hline \multicolumn{7}{|l|}{ Site } \\
\hline Central & $402(41.0)$ & $1592(59.5)$ & & $450(37.2)$ & $1728(59.0)$ & \\
\hline Left sided & $404(41.2)$ & $583(21.8)$ & & $560(46.3)$ & $804 \quad(27.5)$ & \\
\hline Right sided & $40 \quad(4.1)$ & $56 \quad(2.0)$ & & $50 \quad(4.2)$ & $86 \quad(2.9)$ & \\
\hline Submammary & $64 \quad(6.5)$ & $223 \quad(8.3)$ & & $103 \quad(8.5)$ & $149 \quad(5.1)$ & \\
\hline Epigastric & $69(7.0)$ & $218 \quad(8.2)$ & & $44 \quad(3.61)$ & $158 \quad(5.4)$ & \\
\hline Other & $1 \quad(0.1)$ & $7 \quad(0.3)$ & $<0.001$ & $2 \quad(0.2)$ & $4 \quad(0.1)$ & $<0.001$ \\
\hline \multicolumn{7}{|l|}{ Precipitating factor } \\
\hline Nothing & $603(61.5)$ & 1399 (52.3) & & $765(63.3)$ & $1524 \quad(52.0)$ & \\
\hline Exercise & $173(17.7)$ & $752(28.1)$ & & $216(17.9)$ & $958 \quad(32.7)$ & \\
\hline Exercise and rest & $142(14.5)$ & $340(12.7)$ & & $164(13.6)$ & $288 \quad(9.8)$ & \\
\hline Stress & $29 \quad(3.0)$ & 121 & & $27 \quad(2.2)$ & $94 \quad(3.2)$ & \\
\hline Eating & 32 (3.3) & $60 \quad(2.2)$ & & $34 \quad(2.8)$ & $60 \quad(2.1)$ & \\
\hline Other & $1 \quad(0.1)$ & $4 \quad(0.2)$ & $<0.001$ & $3 \quad(0.3)$ & $5 \quad(0.2)$ & $<0.001$ \\
\hline \multicolumn{7}{|l|}{ Character } \\
\hline Aching & $325(33.2)$ & 1059 (39.6) & & 407 (33.7) & 1110 (37.6) & \\
\hline Constricting & $230(23.5)$ & $762(28.5)$ & & $295(24.4)$ & $884 \quad(30.2)$ & \\
\hline Stabbing & $269(27.5)$ & $558(20.9)$ & & $303(25.1)$ & $623(21.3)$ & \\
\hline Nondescript & $156(15.9)$ & 297 (11.1) & $<0.001$ & $204(16.9)$ & $322(11.0)$ & $<0.001$ \\
\hline \multicolumn{7}{|l|}{ Duration } \\
\hline Seconds & $39 \quad(4.0)$ & $147 \quad(5.5)$ & & $69 \quad(5.7)$ & $236 \quad(8.1)$ & \\
\hline$<5 \min$ & $156(15.9)$ & $513(19.2)$ & & $230(19.1)$ & $627 \quad(21.4)$ & \\
\hline $5-15 \mathrm{~min}$ & $226(23.1)$ & $699(26.0)$ & & $269(22.5)$ & $733 \quad(25.0)$ & \\
\hline $15-30 \mathrm{~min}$ & $123(12.6)$ & $259 \quad(9.7)$ & & $129(10.7)$ & $282 \quad(9.6)$ & \\
\hline Hours or variable & $436(44.5)$ & 1058 (39.5) & 0.001 & $512(42.0)$ & 1051 (35.9) & $<0.001$ \\
\hline
\end{tabular}


Table 1: Baseline clinical and chest-pain characteristics of patients included in the study (part 2 of 2)

\begin{tabular}{|c|c|c|c|c|c|c|}
\hline \multirow[b]{2}{*}{ Characteristic } & \multicolumn{3}{|c|}{ Women; no. (\%) of patients* } & \multicolumn{3}{|c|}{ Men; no. (\%) of patients* } \\
\hline & $\begin{array}{c}\text { South Asian } \\
n=980\end{array}$ & $\begin{array}{c}\text { White } \\
n=2676\end{array}$ & $p$ value & $\begin{array}{l}\text { South Asian } \\
n=1209\end{array}$ & $\begin{array}{c}\text { White } \\
n=2929\end{array}$ & $p$ value \\
\hline \multicolumn{7}{|c|}{ Symptom assessment } \\
\hline \multicolumn{7}{|c|}{$\begin{array}{l}\text { Exercise } \\
\text { electrocardiography }\end{array}$} \\
\hline Positive result & $56(12.8)$ & $200(13.2)$ & 0.50 & $126(17.3)$ & $468 \quad(24.0)$ & 0.001 \\
\hline \multicolumn{7}{|c|}{ Cardiologist summary } \\
\hline Typical & $163(16.6)$ & $647(24.2)$ & & $193(16.0)$ & $834 \quad(28.5)$ & \\
\hline Atypical & $817(83.4)$ & $2044(75.8)$ & $<0.001$ & $1016(84.0)$ & 2095 (71.5) & $<0.001$ \\
\hline \multicolumn{7}{|l|}{ Symptom score } \\
\hline Typical & $386(39.4)$ & $1243(46.5)$ & & $492(40.7)$ & 1509 (51.5) & \\
\hline Atypical & $594(60.6)$ & $1433(53.6)$ & $<0.001$ & $717(59.3)$ & $1420(48.5)$ & $<0.001$ \\
\hline
\end{tabular}

Note: $A C E=$ angiotensin-converting enzyme, ASA = acetylsalicylic acid

*Unless stated otherwise.

Asian men. The mean follow-up was 3.05 (standard deviation [SD] 1.84) years. Compared with white women and men, South Asian women and men were younger. Fewer South Asian patients were smokers compared with white patients. There was a higher prevalence of diabetes mellitus among South Asian patients compared with white patients (Table 1).

\section{Chest pain symptoms}

Atypical chest pain was reported by more women than men (symptom score $56.5 \%$ v. $54.5 \%, p=0.054$ ) and by more South Asian people than white people $(59.9 \%$ v. $52.5 \%$, $p<0.001)$. Both South Asian women and men were more likely than white women and men to report atypical symptoms (Table 1). Compared with white patients, South Asian patients were more likely to report pain that was left-sided, stabbing or nondescript, and that lasted for hours or variable periods. South Asian patients were more likely than white patients to report pain that was not associated with exercise. Both South Asian men and women were more likely than white men and women to have their symptoms described as atypical by cardiologists, and they were less likely to receive a diagnosis of angina. There was $73.3 \%$ agreement (kappa statistic 0.43 ) between the cardiologist summary and the symptom score.

Irrespective of sex or ethnic background, patients who reported typical angina symptoms were more likely than those with atypical symptoms to be diabetic, and they more likely to be taking antianginal medications.

\section{Symptoms and diagnosis}

Neither sex nor ethnic background modified the association between exercise electrocardiography results and receiving a diagnosis of angina. There were high likelihood ratios across both sex and ethnic background (Figure 2). After excluding patients with a positive exercise electrocardiography result, cardiologist summaries and typical symptom scores both remained predictive of a diagnosis of angina (Figure 2). Like- lihood ratios were lower for symptom scores compared with cardiologist summaries, but they remained well above 1.0.

\section{Symptoms and prognosis}

We found that typical pain symptoms were associated with coronary outcomes in all patients (Table 2). Using cardiologist summaries, typical pain symptoms were more strongly associated with coronary outcome among women (hazard ratio [HR] 3.74, 95\% CI 2.80-5.01) than among men (HR $1.5195 \%$ CI $1.16-1.97, p<0.001)$. This was also true for symptom scores (women HR 2.30, 95\% CI 1.70-3.11; men HR 1.23, 95\% CI 0.96-1.57, $p=0.002$ ).

Among patients with typical symptoms, women were more likely than men to have coronary outcomes (cardiologist summaries HR 1.49, 95\% CI 1.09-2.04; symptom scores HR 1.39 95\% CI 1.06-1.84) (Table 3). South Asian people with typical pain were as likely as white people with typical pain to experience a coronary outcome for cardiologist summaries (HR $1.27,95 \%$ CI $0.89-1.81)$ and more likely with symptom scores (HR 1.41, 95\% CI 1.04-1.91). Women with atypical pain were less likely than men with atypical pain to experience a coronary outcome (Figure 3) unadjusted log rank test $p=0.001)$. Among South Asian people with atypical pain, the symptom score was associated with coronary outcomes (Figure 3, unadjusted $\log$ rank test $p=0.30$ ). When we examined the adjusted Cox regression hazard ratios, we found that atypical pain had a similar prognostic value for coronary outcomes across sex and ethnic background (Table 3 ). There was no interaction between sex and ethnic background (likelihood ratio for interaction: typical pain $p=0.34$; atypical pain $p=0.76$ ).

\section{Symptoms and clinical management}

Revascularization rates were higher among patients who reported typical symptoms than among those who reported atypical symptoms (women, adjusted HR for revascularization 3.86, 95\% CI 2.35-6.35; South Asian patients, adjusted HR 3.16, 95\% CI 1.93-5.19). However, the rate of revascu- 
Table 2: Type of chest pain (typical v. atypical) as a predictor of coronary outcome, ${ }^{*}$ by sex and ethnic background

\begin{tabular}{|c|c|c|c|c|c|c|}
\hline \multirow[b]{2}{*}{ Method of assessment } & \multicolumn{2}{|c|}{ Typical pain } & \multicolumn{2}{|c|}{ Atypical pain } & \multirow{2}{*}{$\begin{array}{l}\text { Coronary death or acute } \\
\text { coronary syndromes; } \\
\text { adjustedt HR } \\
(95 \% \mathrm{Cl})\end{array}$} & \multirow[b]{2}{*}{$p$ value $\neq$} \\
\hline & $\begin{array}{l}\text { No. of patients } \\
\text { with a coronary } \\
\text { outcome }\end{array}$ & $\begin{array}{c}\text { Total } \\
\text { no. of } \\
\text { patients }\end{array}$ & $\begin{array}{l}\text { No. of patients } \\
\text { with a coronary } \\
\text { outcome }\end{array}$ & $\begin{array}{c}\text { Total } \\
\text { no. of } \\
\text { patients }\end{array}$ & & \\
\hline \multicolumn{7}{|l|}{ Cardiologist summary } \\
\hline Women§ & 141 & 874 & 102 & 3259 & $3.74 \quad(2.80-5.01)$ & $<0.001$ \\
\hline Menๆ & 168 & 1088 & 168 & 3460 & $1.51 \quad(1.16-1.97)$ & \\
\hline \multicolumn{7}{|l|}{ Symptom score } \\
\hline Women§ & 170 & 1796 & 73 & 2337 & $2.30(1.70-3.11)$ & 0.002 \\
\hline Menๆ & 214 & 2070 & 122 & 2478 & $1.23(0.96-1.57)$ & \\
\hline \multicolumn{7}{|l|}{ Cardiologist summary } \\
\hline South Asian patients** & 64 & 356 & 100 & 1833 & $1.97 \quad(1.38-2.81)$ & 0.35 \\
\hline White patients** & 223 & 1481 & 151 & 4124 & $2.41 \quad(1.91-3.05)$ & \\
\hline \multicolumn{7}{|l|}{ Symptom score } \\
\hline South Asian patients** & 97 & 878 & 67 & 1311 & $1.58(1.14-2.18)$ & 0.90 \\
\hline White patients** & 261 & 2663 & 113 & 2942 & $1.62(1.29-2.05)$ & \\
\hline
\end{tabular}

Note: $\mathrm{Cl}=$ confidence interval, $\mathrm{HR}=$ hazard ratio

*Coronary outcomes include death because of coronary artery disease or acute coronary syndromes, and hospital admissions with unstable angina.

†Adjusted for age, sex, ethnic background, diabetes, hypertension, smoking and revascularization.

$\neq p$ value for the difference between 2 hazard ratios. ${ }^{23}$

§Includes both white and Asian women.

IIIncludes both white and Asian men.

**Includes both men and women.

Table 3: Differences in the receipt of angiography and revascularization and in prognosis, by type of chest pain (typical v. atypical) Hazard ratio ( $95 \%$ confidence interval)*

\begin{tabular}{|c|c|c|c|}
\hline \multirow[b]{2}{*}{ Group } & \multicolumn{3}{|c|}{ Hazard ratio $(95 \%$ confidence interval)* } \\
\hline & Coronary angiography* & Revascularization* & $\begin{array}{c}\text { Coronary death or acute } \\
\text { coronary syndromet }\end{array}$ \\
\hline \multicolumn{4}{|l|}{ Women (v. men) } \\
\hline \multicolumn{4}{|l|}{ Typical } \\
\hline Cardiologist summary & $0.68(0.56-0.84)$ & $0.33(0.24-0.46)$ & $1.49(1.09-2.04)$ \\
\hline Symptom score & $0.76(0.63-0.92)$ & $0.40(0.30-0.54)$ & $1.39(1.06-1.84)$ \\
\hline \multicolumn{4}{|l|}{ Atypical } \\
\hline Cardiologist summary & $0.90(0.68-1.19)$ & $0.61(0.39-0.98)$ & $0.83(0.58-1.19)$ \\
\hline Symptom score & $0.87(0.62-1.22)$ & $0.42(0.23-0.78)$ & $0.80(0.51-1.25)$ \\
\hline \multicolumn{4}{|l|}{$\begin{array}{l}\text { South Asian patients } \\
\text { (v. white patients) }\end{array}$} \\
\hline \multicolumn{4}{|l|}{ Typical } \\
\hline Cardiologist summary & $0.58(0.45-0.75)$ & $0.52(0.36-0.75)$ & $1.27(0.89-1.81)$ \\
\hline Symptom score & $0.52(0.41-0.67)$ & $0.53(0.38-0.74)$ & $1.41(1.04-1.91)$ \\
\hline \multicolumn{4}{|l|}{ Atypical } \\
\hline Cardiologist summary & $0.55(0.38-0.78)$ & $0.61(0.35-1.05)$ & $1.38(0.94-2.02)$ \\
\hline Symptom score & $0.59(0.39-0.88)$ & $0.49(0.24-1.00)$ & $1.19(0.73-1.92)$ \\
\hline
\end{tabular}

*Adjusted for age, sex or ethnic background, diabetes, smoking, hypertension, use of secondary prevention or antianginal medications and exercise electrocardiography result.

†Adjusted for age, sex or ethnic background, diabetes, smoking, hypertension, use of secondary prevention medications, revascularization and exercise electrocardiography result. 
larization is largely driven by the severity of angiographic disease, which was not recorded in this study. Women with typical pain were less likely than men with typical pain to receive angiography and revascularization (typical symptom score, adjusted HR for revascularization 0.40, 95\% CI 0.30-0.54) (Table 3). South Asian people with typical or atypical pain were less likely than white people to receive angiography and revascularization (typical symptom score, adjusted HR for angiography 0.52 , 95\% CI $0.41-0.67$; adjusted HR for revascularization $0.53,95 \%$ CI $0.38-0.74$ ).

\section{Interpretation}

We found that typical chest pain was about twice as likely to be associated with adverse outcomes among women than among men. Among those with typical chest pain, there was no difference in prognosis between South Asian and white patients. Thus, women and South Asian patients with prognostically important angina pectoris did not present atypically. Systematic and potentially inequitable differences in management between men and women and between ethnic groups cannot be explained by differences in presentation of symptoms. The central diagnostic cannon of stable angina ${ }^{1}$ for the last 3 decades has assessed pretest probability by use of symptoms, age and sex. Our study demonstrates the validity of this approach for women and extends this approach to include South Asian patients.

Much of the previous research about symptoms in women has focused on suspected acute myocardial infarction rather than stable angina. In women, typical symptoms are more common than atypical symptoms in acute coronary syndromes, ${ }^{24}$ although women tend to have more associated symptoms such as nausea and dyspnea. ${ }^{25}$ In ambulatory settings, women may rate their pain as more intense than men and have more associated symptoms. ${ }^{6}$ In our study, women who attended an ambulatory chest-pain clinic reported more atypical symptoms of angina pectoris than men.

The classification of symptoms as typical or atypical was predictive of the cardiologist's diagnosis of angina in women and men. However, there was prognostic separation between women and men when the classification of symptoms was used to predict outomces. Thus, when comparing risk of coronary death or admission with acute coronary syndrome, typical symptoms were a stronger predictor of coronary outcomes in women than in men. Thus, the phenomenon described as the "Yentl syndrome" (lower use of diagnostic and therapeutic procedures for women and a decreased ability to identify women at risk for acute coronary events) cannot be entirely attributed to atypical symptoms.

We found that typical symptoms were predictive of a diagnosis of angina for both white and South Asian patients. Furthermore, typical symptoms were predictive of coronary outcomes in South Asian patients when compared with atypical presentations. Although South Asian patients attending the chest-pain clinic reported more atypical symptoms than typical symptoms, the rate of subsequent adverse coronary outcomes was similar among both white and South Asian patients with atypical symptoms. Because both doctors and patients may be aware that coronary heart disease mortality is higher among South Asian people, ${ }^{26,27}$ our findings might be explained by a lower threshold for referral of South Asian patients with any chest pain symptoms. Indeed, a previous survey found that South Asian patients with chest pain were more willing than white patients to seek care. ${ }^{9}$ Reassuringly, the prognosis was no worse for South Asian patients than for white patients.

Chest pain characteristics and the perception of pain have been compared in different ethnic groups..$^{10,11}$ Compared with white people, South Asian people report a higher likelihood of seeking care. ${ }^{9}$ In a prospective study based in an emergency department, African-American patients were more likely than white patients to attribute their symptoms to a noncardiac source, but they were not more likely than white patients to have atypical symptoms. ${ }^{28}$ When presenting for coronary angiography, African-American patients have been reported to complain more of shortness of breath more often than white patients. ${ }^{29}$
A

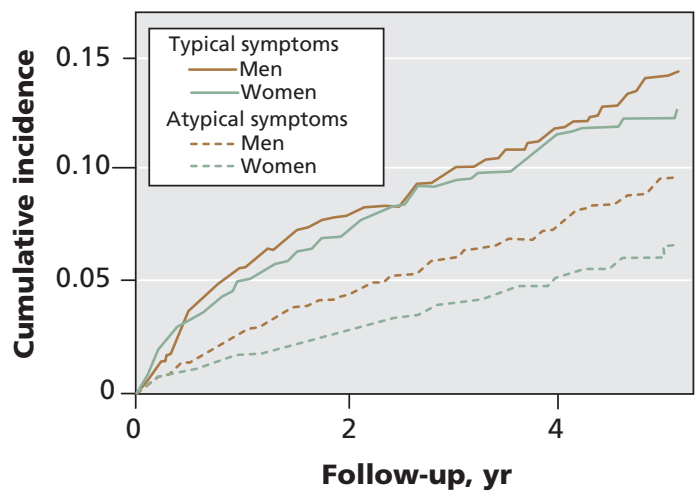

B

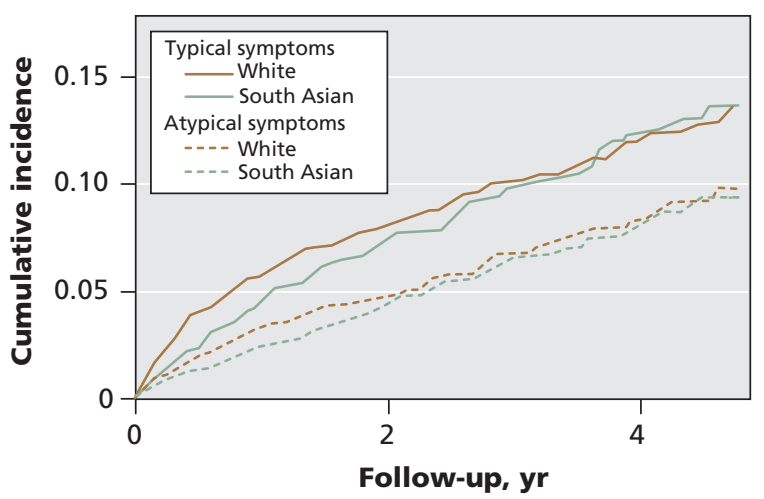

Figure 3: Cumulative incidence of mortality because of coronary artery disease or acute coronary syndromes among men and women (A) ( $p=0.30$ for typical symptoms, $p=0.001$ for atypical symptoms) and among white and South Asian patients ( $p=0.53$ for typical symptoms, $p=0.88$ for atypical symptoms). 
We found lower rates of coronary angiography and revascularization among women and South Asian patients compared with men and white patients. This could not be fully explained by the presence of typical or atypical symptoms despite the fact that women and South Asian patients with typical pain were less likely to undergo diagnostic and therapeutic invasive procedures. Studies of such inequalities in management among women have lacked details about pain symptoms. We have also shown that an atypical presentation of chest pain cannot explain undermanagement. It is also unlikely that differences in symptom severity explain this undermanagement because functional impact and tendency to seek care are greater among women and South Asian people with chest pain.,30

In our study, a history of typical pain symptoms, based on predefined response categories to 4 questions (character, site, duration, precipitating factor) was associated with a diagnosis of angina and a worse prognosis for coronary outcomes among women and South Asian patients. Rather than using a more detailed risk score, a general practitioner could quickly determine the symptom score from the patient's history and decide whether referral to a chest-pain clinic is necessary. ${ }^{31,32}$ Compared with the symptom score, the cardiologist summary was more strongly associated with a diagnosis of angina or risk of coronary outcomes, which may reflect the incorporation of risk factor information and clinical experience into the estimate of pretest disease likelihood. Although it was a weaker predictor of outcome, the symptom score was predictive. Thus, we encourage general practitioners to use a simple and quick patient history to determine appropriateness for referral to a cardiologist, potentially helping to overcome inequitable barriers to referral. ${ }^{33}$

\section{Strengths and limitations}

A major strength of our study is the detailed description of chest pain among a large number of people with recent-onset symptoms who had not had a previous investigation for angina and who had not had a previous myocardial infarction or revascularization. The duration of symptoms was less than 6 months for $87 \%$ of patients.

Several limitations should be considered in interpreting our findings. First, the recorded patient history may have been biased by the knowledge of the exercise electrocardiography findings. For this reason, we excluded patients with an abnormal exercise electrocardiograpy results when assessing the diagnosis of angina. However, our finding of the prognostic importance of typical symptoms among women and South Asians would not have been affected by this bias. Second, the South Asian ethnic background encompasses people of different languages, religions and cultural groups, among whom the cardiovascular risk profile may differ. ${ }^{7}$ Further research is required to determine whether symptom validity differs between patients of Bangladeshi, Indian, Pakistani or Sri Lankan descent. Third, data were not available on the findings of angiography.

A potential limitation of our quantitative study is that the actual words used by patients, their meaning and context were not reported. We addressed this in a separate ethnographic qualitative study of 59 clinic consultations to understand how the chest pain classification and diagnosis were reached. ${ }^{34} \mathrm{We}$ found that symptom history represents a complex negotiation between cardiologist and patient, with much ambiguity and re-telling. There was little evidence that this negotiation was patterned by sex or ethnic background. Importantly, none of the South Asian patients in our study relied on translators; the minority who needed help with English were accompanied by a family member. We relied on the prespecified coding in the database; it is likely that doctors may record in free text further relevant details of symptoms pertinent to the diagnosis of angina. We have demonstrated that electronic processing of this natural language might aid the identification of patients with angina. ${ }^{35}$

\section{Conclusion}

Women and South Asian people with typical chest pain were at increased risk of adverse coronary outcomes compared with those who presented with atypical pain. Women and South Asian people with clinically important angina pectoris did not present atypically, and differences in symptom description did not account for their lower rates of coronary angiography and revascularization compared with men and white patients. Thus, symptoms of chest pain are valid diagnostic and potentially relevant prognostic tools across sex and ethnic backgrounds. Further study should examine why South Asian patients and white women with the same prognosis as men receive poorer care.

This article has been peer reviewed.

\section{Competing interests: None declared.}

Contributors: M. Justin Zaman and Cornelia Junghans conceived the study idea. M. Justin Zaman performed the statistical analyses, wrote the first draft of the manuscript and is the guarantor. Ruoling Chen and Cornelia Junghans were involved in the data analyses. Gene S. Feder and Neha Sekhri were involved in writing the discussion and interpretation. Adam D. Timmis designed the database, organized the cohort and was involved in writing the discussion and interpretation. Harry Hemingway contributed to the first draft and the analyses, and he was involved in the discussion and interpretation. All authors participated in the discussion and interpretation of the final results, contributed to the final paper and approved the final version submitted for publication.

Acknowledgements: We thank the staff at the study hospitals for their cooperation in this study.

M. Justin Zaman is supported by a British Heart Foundation Clinical PhD Studentship (FS/04/062). The funding body was not involved in the study design or analysis.

\section{REFERENCES}

1. Diamond GA, Forrester JS. Analysis of probability as an aid in the clinical diagnosis of coronary-artery disease. N Engl J Med 1979;300:1350-8.

2. Hemingway $\mathrm{H}$, Langenberg $\mathrm{C}$, Damant $\mathrm{J}$, et al. Prevalence of angina in women versus men: a systematic review and meta-analysis of international variation across 31 countries. Circulation 2008;117:1526-36.

3. Bajekal M, Becher H, Boreham R, et al. Health Survey for England 1999: the health of minority ethnic groups. London: The Stationery Office; 2001. Available: www.archive.official-documents.co.uk/document/doh/survey99/hse99.htm (accessed 2008 July 3).

4. Philpott S, Boynton PM, Feder G, et al. Gender differences in descriptions of angina symptoms and health problems immediately prior to angiography: the ACRE study. Appropriateness of Coronary Revascularisation study. Soc Sci Med 2001;52:1565-75.

5. Sheps DS, Kaufmann PG, Sheffield D, et al. Sex differences in chest pain in patients with documented coronary artery disease and exercise-induced ischemia: results from the PIMI study. Am Heart J 2001;142:864-71.

6. D'Antono B, Dupuis G, Fleet R, et al. Sex differences in chest pain and prediction of exercise-induced ischemia. Can J Cardiol 2003;19:515-22.

7. Bhopal R, Fischbacher C, Vartiainen E, et al. Predicted and observed cardiovascu- 
lar disease in South Asians: application of FINRISK, Framingham and SCORE models to Newcastle Heart Project data. J Public Health (Oxf) 2005;27:93-100.

8. Barakat K, Wells Z, Ramdhany S, et al. Bangladeshi patients present with nonclassic features of acute myocardial infarction and are treated less aggressively in east London, UK. Heart 2003;89:276-9.

9. Chaturvedi N, Rai H, Ben-Shlomo Y. Lay diagnosis and health-care-seeking behaviour for chest pain in south Asians and Europeans. Lancet 1997;350:1578-83.

10. Raczynski JM, Taylor H, Cutter G, et al. Diagnoses, symptoms, and attribution of symptoms among black and white inpatients admitted for coronary heart disease. Am J Public Health 1994;84:951-6.

11. Meshack AF, Goff DC, Chan W, et al. Comparison of reported symptoms of acute myocardial infarction in Mexican Americans versus non-Hispanic whites (the Corpus Christi Heart Project). Am J Cardiol 1998;82:1329-32.

12. Douglas PS, Ginsburg GS. The evaluation of chest pain in women. $N$ Engl J Med 1996;334:1311-5

13. Umachandran V, Ranjadayalan $\mathrm{K}$, Ambepityia G, et al. The perception of angina in diabetes: relation to somatic pain threshold and autonomic function. Am Heart $J$ 1991;121:1649-54

14. Hemingway H, McCallum A, Shipley M, et al. Incidence and prognostic implications of stable angina pectoris among women and men. JAMA 2006;295:1404-11.

15. Alter DA, Naylor CD, Austin P, et al. Effects of socioeconomic status on access to invasive cardiac procedures and on mortality after acute myocardial infarction. $N$ Engl J Med 1999;341:1359-67.

16. Feder G, Crook AM, Magee P, et al. Ethnic differences in invasive management of coronary disease: prospective cohort study of patients undergoing angiography. BMJ 2002;324:511-6.

17. Sekhri N, Timmis A, Chen R, et al. Inequity of access to investigation and effect on clinical outcomes: prognostic study of coronary angiography for suspected stable angina pectoris. BMJ 2008;336:1058-61.

18. Chapple A, Gatrell A. Variations in use of cardiac services in England: perceptions of general practitioners, general physicians and cardiologists. J Health Serv Res Policy 1998;3:153-8.

19. Spertus JA, Winder JA, Dewhurst TA, et al. Development and evaluation of the Seattle Angina Questionnaire: a new functional status measure for coronary artery disease. J Am Coll Cardiol 1995;25:333-41.

20. Ray S, Archbold RA, Preston S, et al. Computer-generated correspondence for patients attending an open-access chest pain clinic. J R Coll Physicians Lond 1998; 32:420-1

21. Sekhri N, Feder GS, Junghans C, et al. How effective are rapid access chest pain clinics? Prognosis of incident angina and non-cardiac chest pain in 8762 consecutive patients. Heart 2007;93:458-63.
22. Hemingway $\mathrm{H}$, Chen R, Junghans $\mathrm{C}$, et al. Appropriateness criteria for coronary angiography in angina: reliability and validity. Ann Intern Med 2008;149:221-31.

23. Altman DG, Bland JM. Statistics Notes: Interaction revisited: the difference between two estimates. BMJ 2003;326:219.

24. Patel H, Rosengren A, Ekman I. Symptoms in acute coronary syndromes: Does sex make a difference? Am Heart J 2004;148:27-33.

25. DeVon HA, Zerwic JJ. Symptoms of acute coronary syndromes: Are there gender differences? A review of the literature. Heart Lung 2002;31:235-45.

26. Wild S, McKeigue P. Cross sectional analysis of mortality by country of birth in England and Wales, 1970-92. BMJ 1997;314:705-10.

27. Harding S, Rosato M, Teyhan A. Trends for coronary heart disease and stroke mortality among migrants in England and Wales, 1979-2003. slow declines notable for some groups. Heart 2007.

28. Klingler D, Green-Weir R, Nerenz D, et al. Perceptions of chest pain differ by race. Am Heart J 2002;144:51-9.

29. Hravnak M, Whittle J, Kelley ME, et al. Symptom expression in coronary heart disease and revascularization recommendations for black and white patients. Am J Public Health 2007;97:1701-8.

30. Hemingway $\mathrm{H}$, Vahtera J, Virtanen $\mathrm{M}$, et al. Outcome of stable angina in a working population: the burden of sickness absence. Eur J Cardiovasc Prev Rehabil 2007;14:373-9.

31. Clayton TC, Lubsen J, Pocock SJ, et al. Risk score for predicting death, myocardial infarction, and stroke in patients with stable angina, based on a large randomised trial cohort of patients. BMJ 2005;331:869.

32. Daly CA, De Stavola B, Sendon JL, et al. Predicting prognosis in stable anginaresults from the Euro heart survey of stable angina: prospective observational study. BMJ 2006;332:262-7.

33. Gardner K, Chapple A. Barriers to referral in patients with angina: qualitative study. BMJ 1999;319:418-21.

34. Somerville C, Featherstone K., Hemingway H., et al. Performing stable angina pectoris: an ethnographic study. Soc Sci Med 2008;66:1497-508.

35. Pakhomov SS, Hemingway H, Weston SA, et al. Epidemiology of angina pectoris: role of natural language processing of the medical record. Am Heart J 2007; 153:666-73.

Correspondence to: Dr. M. Justin Zaman, Department of Epidemiology and Public Health, University College London, 1-19 Torrington Place, London UK WC1E6BT; j.zaman@ucl.ac.uk

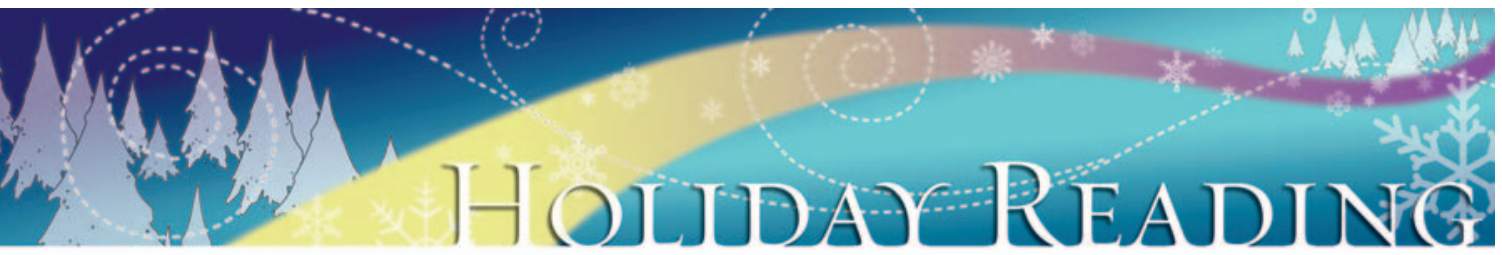

\section{Call for submissions}

Do you have something profound or profoundly entertaining to say? CMAJ may be just the place to publish. In December 2008, we will present a special Holiday Reading section featuring essays, creative non-fiction, short fiction and narrative medicine. Your missive can be personal or academic, frankly serious or gratuitously entertaining; the common thread is medicine in all its permutations.

Articles should be no longer than 1200 words. Send your submissions for consideration via our online manuscript system (http://mc.manuscriptcentral.com/cmaj). Please mention in your cover letter that your submission is intended for this year's Holiday Reading issue.

The deadline for submissions is Oct. 7, 2008. 